\title{
Human and Viral microRNA Expression in Sjögren Syndrome
}
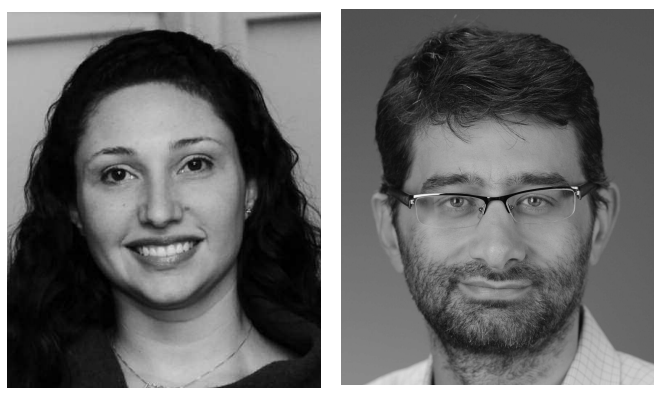

Sjögren syndrome (SS) is one of the most common autoimmune diseases, and mainly affects women. It is characterized by features of systemic autoimmunity and dysfunction and inflammation in the exocrine glands. The dysfunction of the salivary glands often causes significant morbidity and has social implications. In a significant percentage of affected patients, extraglandular manifestations lead to systemic diseases with serious medical implications as more major organs are affected. Non-Hodgkin lymphoma is another major complication of SS, occurring in $5 \%$ of patients. The pathogenesis of SS has not been delineated, but it is believed that both immunologic and nonimmune mechanisms are involved.

In this issue of The Journal, Peng, et al, report their findings of microRNA profiling of peripheral mononuclear cells of primary SS (pSS) in a Chinese patient cohort ${ }^{1}$. Four patients with pSS and 3 healthy controls were profiled with microarrays and some of the most differentially expressed microRNA were validated with quantitative real-time PCR in a total of 33 pSS patient and 10 healthy control samples, including the samples used for microarrays. After all analyses, miRNA-146a, miRNA-155, and miRNA-181a were found to be the most differentially expressed. Not surprisingly, those microRNA have previously been associated with autoimmune diseases and immune microRNA studies.

miRNA-146a is a very interesting microRNA involved in several biological functions and diseases, from acquired immunity ${ }^{2}$ to cancer $^{3,4}$. miRNA-146a has been shown to be a negative regulator of nuclear factor- $\mathrm{KB}$ activation through regulation of IRAK1/TRAF6 of the MyD88-dependent pathway ${ }^{5}$. In autoimmune diseases, it has been shown to be downregulated in the peripheral mononuclear cells of patients with systemic lupus erythematosus but upregulated in patients with rheumatoid arthritis ${ }^{5,6}$. miRNA-146a has also previously been associated with SS and was shown to be upregulated in peripheral mononuclear cells ${ }^{7}$. Similarly to miRNA-146a, miRNA-155 has also been implicated in a variety of pathologies ${ }^{8,9,10}$. However, in the case of SS and in relation to the viral differentially expressed microRNA reported in this article, the relation of miRNA-155 to Epstein-Barr virus infection (EBV) ${ }^{11,12}$ and the association of this microRNA to lymphomas deserve further evaluation ${ }^{13,14,15}$.

The finding that the overexpression of miRNA-181a is attributed to the B cells and not the T cells of patients with pSS, yet there was no clinical correlation of the level of expression of this microRNA except for antinuclear antibody, is intriguing for a number of reasons. First, it shows that overexpression of this microRNA does not correlate with disease activity and chronicity and thus it might be one of the first and constant molecular alterations that occurs in pSS B cells. Second, measures of the relative level of miRNA-181a in B and T cells might prove to be a biomarker for pSS. Finally, knowing the exact cell type of a dysregulated microRNA greatly facilitates the study of its role in disease, because the functional effect of a microRNA is in many cases tissue dependent. This has already been shown to be the case for miRNA-181a in hematopoiesis. In one of the seminal articles examining the role of microRNA in hematopoiesis ${ }^{16}$, mouse bone marrow cells were infected with a retrovirus expressing miRNA-181a and were then transplanted into lethally irradiated mice, allowing the infected cells to reconstitute all blood lineages. Examination of the lineage composition of peripheral blood cells originating from the infected cells showed that miRNA-181a expression increased the number of $\mathrm{B}$ lymphoid cells, with a concurrent decrease in T lymphoid cells, especially CD8+. Because the differentiation of $\mathrm{B}$ and $\mathrm{T}$ cells is developmentally independent, the functional role of miRNA-181a in those cells is vastly different. Another finding from that study is that in murine bone marrow cells, miRNA-181a expression was low in pre-B progenitor cells and upregulated in differentiated mature B lymphocytes. Identifying the molecular trigger of this upregulation only in B cells will contribute to our limited understanding of disease

See Elevated miRNA-181a levels in pSS PBMC, page 2208

Personal non-commercial use only. The Journal of Rheumatology Copyright (c) 2014. All rights reserved. 
pathogenesis in SS and help in the development of targeted therapies.

Another very interesting finding from this microRNA profiling is the simultaneous overexpression of viral microRNA in blood mononuclear cells. This finding is in accordance with a previous study that identified many of the same viral microRNA unregulated in the salivary glands of $\mathrm{pSS}^{17}$.

Viral microRNA function in host cells, their interaction with cellular microRNA, and the relation of viral microRNA to stage of the viral life cycle have not been studied for the majority of viral microRNA. In the present $\operatorname{article}^{1}$, the presence of EBV microRNA and the upregulation of miRNA-181a in B cells, which are the only lymphatic cells known to be infected by EBV, generate interesting questions about the possibility of a viral microRNA driving the expression of a cellular microRNA in a specific cell type promoting a disease phenotype.

The interplay between viral infections and viral and cellular microRNA in the pathogenesis of autoimmune diseases is difficult to delineate, but the presence and differential expression of the viral microRNA in a number of pathologies suggest that they might play crucial roles in complex diseases, especially ones in which environmental factors have been shown to be contributing factors.

\section{ANA P. COTRIM, DDS, PhD, ILIAS ALEVIZOS, DMD,}

SS and Salivary Gland Dysfunction Unit,

Molecular Physiology and Therapeutics Branch,

National Institute of Dental and Craniofacial Research (NIDCR), National Institutes of Health (NIH),

Bethesda, Maryland, USA.

Supported by the Intramural Research Program of NIH, NIDCR. Address correspondence to Dr. Alevizos, SS and Salivary Gland Dysfunction Unit, Molecular Physiology and Therapeutics,

National Institute of Dental and Craniofacial Research,

10 Center Drive, Bldg. 10, Rm 1N110, Bethesda, Maryland 20892, USA

\section{REFERENCES}

1. Peng L, Ma W, Yi F, Yang Y-J, Lin W, Chen H, et al. MicroRNA profiling in Chinese patients with primary SS reveals elevated miRNA-181a in peripheral blood mononuclear cells. J Rheumatol 2014:41:2208-13.

2. Lu LF, Boldin MP, Chaudhry A, Lin LL, Taganov KD, Hanada T, et al. Function of miR-146a in controlling Treg cell-mediated regulation of Th1 responses. Cell 2010;142:914-29.
3. Zhao JL, Starczynowski DT. Role of microRNA-146a in normal and malignant hematopoietic stem cell function. Front Genet 2014;5:219.

4. Yao Q, Cao Z, Tu C, Zhao Y, Liu H, Zhang S. MicroRNA-146a acts as a metastasis suppressor in gastric cancer by targeting WASF2. Cancer Lett 2013;335:219-24.

5. Chan EK, Ceribelli A, Satoh M. MicroRNA-146a in autoimmunity and innate immune responses. Ann Rheum Dis 2013;72 Suppl 2:ii90-5.

6. Nakasa T, Miyaki S, Okubo A, Hashimoto M, Nishida K, Ochi M, et al. Expression of microRNA-146 in rheumatoid arthritis synovial tissue. Arthritis Rheum 2008;58:1284-92.

7. Zilahi E, Tarr T, Papp G, Griger Z, Sipka S, Zeher M. Increased microRNA-146a/b, TRAF6 gene and decreased IRAK1 gene expressions in the peripheral mononuclear cells of patients with Sjogren's syndrome. Immunol Lett 2012;141:165-8.

8. Corral-Fernández NE, Salgado-Bustamante M, Martínez-Leija ME, Cortez-Espinosa N, García-Hernández MH, Reynaga-Hernández E, et al. Dysregulated miR-155 expression in peripheral blood mononuclear cells from patients with type 2 diabetes. Exp Clin Endocrinol Diabetes 2013;121:347-53.

9. Gombos K, Horváth R, Szele E, Juhász K, Gocze K, Somlai K, et al. miRNA expression profiles of oral squamous cell carcinomas. Anticancer Res 2013;33:1511-7.

10. Montagner S, Orlandi EM, Merante S, Monticelli S. The role of miRNAs in mast cells and other innate immune cells. Immunol Rev 2013;253:12-24.

11. Cameron JE, Fewell C, Yin Q, McBride J, Wang X, Lin Z, et al. Epstein-Barr virus growth/latency III program alters cellular microRNA expression. Virology 2008;382:257-66.

12. Motsch N, Pfuhl T, Mrazek J, Barth S, Grässer FA. Epstein-Barr virus-encoded latent membrane protein 1 (LMP1) induces the expression of the cellular microRNA miR-146a. RNA Biol 2007;4:131-7.

13. Liu C, Iqbal J, Teruya-Feldstein J, Shen Y, Dabrowska MJ, Dybkaer $\mathrm{K}$, et al. MicroRNA expression profiling identifies molecular signatures associated with anaplastic large cell lymphoma. Blood 2013;122:2083-92.

14. Peveling-Oberhag J, Crisman G, Schmidt A, Döring C, Lucioni M, Arcaini L, et al. Dysregulation of global microRNA expression in splenic marginal zone lymphoma and influence of chronic hepatitis C virus infection. Leukemia 2012;26:1654-62.

15. Takacs M, Segesdi J, Banati F, Koroknai A, Wolf H, Niller HH. The importance of epigenetic alterations in the development of Epstein-Barr virus-related lymphomas. Mediterr J Hematol Infect Dis 2009;1:e2009012.

16. Chen CZ, Li L, Lodish HF, Bartel DP. MicroRNAs modulate hematopoietic lineage differentiation. Science 2004;303:83-6.

17. Alevizos I, Alexander S, Turner RJ, Illei GG. MicroRNA expression profiles as biomarkers of minor salivary gland inflammation and dysfunction in Sjogren's syndrome. Arthritis Rheum 2011;63:535-44.

J Rheumatol 2014;41:2102-3; doi:10.3899/jrheum.141068 